\title{
FORMULATION DEVELOPMENT AND EVALUATION OF NASAL IN-SITU GEL OF FLUTICASONE PROPIONATE
}

\section{R. B. SAUDAGAR ${ }^{*}$, SARIKA V. KHANDBAHALE ${ }^{2}$}

${ }^{1 *}$ Department of Pharmaceutical Chemistry, R. G. Sapkal College of Pharmacy, Anjaneri, Nashik 422213, Maharashtra, India, ${ }^{2}$ Department of Quality Assurance Techniques, R. G. Sapkal College of Pharmacy, Anjaneri, Nashik 422213, Maharashtra, India

Email: sarikavkhandbahale@gmail.com

Received: 20 May 2017, Revised and Accepted: 22 Jul 2017

\begin{abstract}
Objective: Over a few decades, advances in the in-situ gel technologies have spurred development in may medical and biomedical applications including controlled drug delivery. For locally acting intra nasal drugs, an extended residence time in the nasal cavity is desirable and related to a prolonged effect. The aim of the present work was to design a nasal delivery system with improved mucoadhesive properties that could provide prolonged retention time for the treatment of the allergic rhinitis.
\end{abstract}

Methods: A $3^{2}$ factorial design was used to investigate the effect of the amount of Poloxamer 188 and carbopol 934 as independent variables. \% drug release and mucoadhesive strength were taken as dependent variables. The formulations were tested for gelation study, viscosity study, gel strength, mucoadhesion study, drug content and stability study. Gelation was determined by physical appearance, viscosity study of solution and gel formulations indicated that increase in polymer concentration increase the viscosity.

Results: Gel strength was found in the range of 0.55-2.36 sec. The mucoadhesive force in terms of detachment stress increase with an increase in the concentration of carbopol 934. A stability study for optimized formulation as per ICH guideline for $90 \mathrm{~d}$ showed no change in pH, drug content and viscosity.

Conclusion: The developed in-situ gelling system for Fluticasone Propionate using poloxamer188 in combination with carbopol 934 with improved mucoadhesive properties that could provide prolonged retention time for the treatment of allergic rhinitis.

Keywords: $3^{2}$ factorial design, In-situ nasal gel, Fluticasone Propionate, Mucoadhesive

(C) 2017 The Authors. Published by Innovare Academic Sciences Pvt Ltd. This is an open access article under the CC BY license (http://creativecommons.org/licenses/by/4.0/) DOI: http://dx.doi.org/10.22159/ijcpr.2017v9i5.22135

\section{INTRODUCTION}

Nasal therapy is the recognised form of treatment in Ayurvedic systems of Indian medicine. It is also called as nasaya karma. The nasal mucosa itself and the drug delivery systems affect drug absorption through the nasal route and is invaluable. A stable, safe and effective nasal product can be developed through appropriate and adequate pre-formulation studies of the drug. Nasal drug delivery system provides excess of easy application of drug with the possibility of self-administration by removing the chance of unwanted painful condition associated with injection form of drug delivery $[1,2]$. The greater permeability of nasal mucosa with large surface area affords a rapid onset of therapeutic effect. The appealing advantage of nasal drug delivery is the possibility of targeting central nervous system (CNS) by passing blood brain barrier (BBB). The drug absorbed nasally via. Olfactory epithelium are reported to enter in the olfactory neurons and supporting cells and subsequently into the brain, which reduced not only the systemic toxicity of centrally acting drugs but also enhanced therapeutic efficacy. Nasal route is the route of choice for rapid mass immunization in developing countries. Despite having a large number of advantages, the bioavailability of nasal dosage form is hindered. poloxamer 188 generally occurs as white, free flowing prilled granules, or as cast solids. They are practically odourless and tasteless. Poloxamers are stable materials and their aqueous solutions are stable in the presence of acids, alkalis and metal ions. However, aqueous solutions support mold growth. It contains less than $0.5 \% \mathrm{w} / \mathrm{w}$ water and are hygroscopic only at a relative humidity greater than $80 \%$. Poloxamers are used in a variety of oral, parenteral and topical pharmaceutical formulations and are generally regarded as non-toxic and non-irritant materials. Poloxamers are not metabolized in the body [3].

Carbopol is white coloured, Fluffy, acidic, hygroscopic powders with a slight characteristics odor. Carbomerrange are synthetic high molecular weight cross linked polymers of acrylic acid, which confirm to USP/INF. They are water soluble polymer used to thicken to produce a wide range of viscosities and flow properties. It is suspended soluble ingredient and it will stabilize and emulsify emulsion. The decomposition of carbopol 934 occurs within $30 \mathrm{~min}$ at $260{ }^{\circ} \mathrm{C}$. It is Mucoadhesive, emulsifying agent, release modifying agent, suspending agent, tablet binder, viscosity increasing agent [3].

The Fluticasone Propionate has a high therapeutic index and efficacy. The drugs have been used successfully for several years for all severties of asthma and have proved to be well tolerated. No clinically important systemic effects are reported for the normal therapeutic range. By contrast, pharmacokinetic studies have suggested hypothalamic-pituitary-adrenal suppression with higher doses. However, those studies involved normal volunteers or patients who had mild asthma and were receiving inappropriately high doses, well in excess of those needed to control their disease. In patients with moderate or severe asthma requiring higher doses of inhaled corticosteroids, factors such as airflow obstruction and ventilation perfusion mismatch could alter drug deposition in the lung and change systemic absorption [4].

An attempt was made to develop the temperature sensitive nasal Insitu gel Fluticasone Propionate $(2 \%)$ for controlling the drug release in the nasal tissues. Two polymers have been used i.e. Poloxamer 188 and carbopol 934. Poloxamer 188 is Temperature sensitive and act as a gelling agent and carbopol 934 is the $\mathrm{pH}$ sensitive mucoadhesive polymer [5].

\section{MATERIALS AND METHODS}

Poloxamer 188 was purchased from BASF chemicals, Mumbai, and Carbopol 934 from Loba Chemie, Pvt. Ltd. India.

\section{Methods}

Gel was prepared by cold technique method. The Poloxamer 188 and Carbopol 934 was dissolved completely in distilled water and allow 
to hydrate for overnight. The $2 \%$ of drug solution was addedin distilled water and Propylene glycol $0.1 \% \mathrm{v} / \mathrm{v}$. then Benzalkonium chloride was added as a preservative in the above solution. On next day both the solution were mixed together with continues stirring under cold condition. This resultanting formulation was kept overnight in a refrigerator until a clear solution was obtained [5].

\section{Preformulation study of drug $[5,6]$}

Preformulation can be described as the step that deals with the acquisition of data on the drug compound and its excipients, which are then analyzed or processed into information, and ultimately transformed into knowledge in the form of a recommended formulation. The area of preliminary-preformulation represents the scope of activities that facilitate the design of preformulation studies and is often theoretical in nature. Preformulation testing is the first step in the rational development of dosage forms of a drug substance. It can be defined as an investigation of physical and chemical properties of a drug substance alone and when combined with excipients. The overall objective of preformulation testing is to generate information useful to the formulator in developing stable and bioavailable dosage forms that can be mass produced.

\section{Description}

Drug sample was evaluated for color and texture.

\section{Melting point}

The melting point of Fluticasone Propionate was determined by taking a small amount of sample in a capillary tube closed at one end and placed in melting point apparatus. The melting point was noted in triplicate.

\section{Solubility}

The solubility of Fluticasone Propionate was checked in different solvents like distilled water, $\mathrm{Hcl}(0.1 \mathrm{~N})$, methanol, $\mathrm{NaOH}$, Acetone, phosphate buffer (pH 6.8 and 7.4).

\section{Ultraviolet-visible spectroscopy $[7,8]$}

\section{Determination of $\lambda \max$ in methanol}

The UV spectrum of Fluticasone Propionate was obtained using Ultraviolet Spectrophotometer (shimadzu 1800 series). Accurately weighed $10 \mathrm{mg}$ of the drug was dissolved in sufficient quantity of Methanol and volume was made up to $100 \mathrm{ml}$ to obtain a concentration of $100 \mu \mathrm{g} / \mathrm{ml} .1 \mathrm{ml}$ of the aliquot was withdrawn and volume was made up to $10 \mathrm{ml}$ using Methanol to obtain the concentration of $10 \mu \mathrm{g} / \mathrm{ml}$. The resultant solutions scanned from $200-400 \mathrm{~nm}$ and the spectrum was recorded to obtain the value of maximum wavelength.

\section{Determination of $\lambda \max$ in phosphate buffer $\mathrm{pH} 6.8$}

Fluticasone Propionate $(10 \mathrm{mg})$ was weighed accurately and transferred to $100 \mathrm{ml}$ volumetric flask. It was then dissolved in little quantity of Methanol and diluted up to $100 \mathrm{ml}$ with phosphate buffer $\mathrm{pH}$ 6.8. The stock solution of $100 \mu \mathrm{g} / \mathrm{ml}$ was used to prepare different dilutions in the range of $2-20 \mu \mathrm{g} / \mathrm{ml}$. The absorbance of resulting solutions were measured at $239 \mathrm{~nm}$ using phosphate buffer $\mathrm{pH} 6.8$ as a blank by UV-visible spectrophotometer.

\section{Fourier transform Infrared spectroscopy (FTIR) [9]}

The FTIR spectra of pure drug and physical mixture (Drug+Poloxamer 188+Carbopol 934) was carried out. The physical mixture were prepared and sample kept for 1 mo at $40{ }^{\circ} \mathrm{C}$. The infrared absorption spectrum of drug and physical mixture of drug and polymers was recorded with the wave number $4000-400 \mathrm{~cm}^{-1}$.

\section{Formulation and development of nasal in-situ gel of fluticasone propionate}

The quantities of drug and other ingredients were weighed and formulation were prepared in following manner:

\section{Cleaning of glassware and container}

All the glassware's were washed with distilled water and then sterilized by drying at $160^{\circ} \mathrm{C}$ for $1 \mathrm{hr}$ in hot air oven.

\section{Preparation of solution'A'}

Accurately weighed quantity ( $0.2 \mathrm{gm})$ of Fluticasone Propionate and was dissolved in Isopropyl alcohol.

\section{Preparation of polymer dispersion 'B'}

Poloxamer188 and carbopol were dissolved in water under a cold condition with continuous stirring. And the solution was kept to hydrate for $12 \mathrm{hr}$ to produce a clear solution.

\section{Mixing}

After $12 \mathrm{~h}$ both the solution A and B were mixed together under a cold condition with continuous stirring.

\section{Aseptic filling to container}

The formulation was aseptically transferred to previously sterilized glass vials and sealed.

\section{Formulation optimization}

$3^{2}$ full factorial design was applied to the formulation that showed the satisfactory results. To see the effects of conc. of variables Poloxamer 188 and Carbopol 934 on various responses like \% drug release the composition of all batches is shown in table 1 .

Table 1: Composition of formulation batches as per $3^{2}$ facorial design

\begin{tabular}{|c|c|c|c|c|c|c|c|c|c|}
\hline $\begin{array}{l}\text { Formulation code } \\
\text { Ingredient }\end{array}$ & F1 & F2 & F3 & F4 & F5 & F6 & F7 & F8 & F9 \\
\hline Fluticasone Propionate (\% w/v) & 0.2 & 0.2 & 0.2 & 0.2 & 0.2 & 0.2 & 0.2 & 0.2 & 0.2 \\
\hline Poloxamer-188 (\%w/v) & 14 & 16 & 18 & 14 & 16 & 18 & 14 & 16 & 18 \\
\hline Carbopol-934 (\%w/v) & 0.1 & 0.1 & 0.1 & 0.15 & 0.15 & 0.15 & 0.2 & 0.2 & 0.2 \\
\hline Propylene Glycol (\%w/v) & 0.01 & 0.01 & 0.01 & 0.01 & 0.01 & 0.01 & 0.01 & 0.01 & 0.01 \\
\hline BenzalkoniumChloride (\%w/v) & 1 & 1 & 1 & 1 & 1 & 1 & 1 & 1 & 1 \\
\hline Triethanolamine & q. s. & q. s. & q. s. & q. s. & q. s. & q. s. & q. s. & q. s. & q. s. \\
\hline Purified water (ml) & 100 & 100 & 100 & 100 & 100 & 100 & 100 & 100 & 100 \\
\hline Iso Propyl alcohol (ml) & 5 & 5 & 5 & 5 & 5 & 5 & 5 & 5 & 5 \\
\hline
\end{tabular}

\section{Evaluation of Gel [10]}

\section{Clarity}

The clarity of the gel was done by visual inspection under black and white background.

\section{pH}

$\mathrm{pH}$ of each formulation was determined by using Digital $\mathrm{pH}$ meter(sistronic Digital pH meter 335) was previously calibrated by
pH 4 and $\mathrm{pH}$ 7. The $\mathrm{pH}$ values were recorded immediately after preparation.

\section{Rheological study}

\section{Viscosity [11]}

The rheological properties of gels were determined by the Brookfield Viscometer; type DV-II+PRO using spindle no. LV 3(63). Viscosities of the formulations were taken at two different temperatures i.e. at Room temperature and at $37^{\circ} \mathrm{C}$ with varying shear rate. 


\section{Measurement of gelling capacity}

The gelling capacity of the formulations was determined by placing 1 drop of the prepared formulation into a vial containing $2 \mathrm{ml}$ of freshly prepared SNF solution. Gelation was assessed visually and noting the time for the gelation and the time taken for the gel formed to dissolve.

\section{Gel strength}

A sample of $25 \mathrm{ml}$ of gel was put in a $50 \mathrm{ml}$ graduated cylinder. A weight of $14.33 \mathrm{gm}$ was placed on the gel surface. The gel strength which is an indication for the gel at physiological temperature was determined by the time in seconds required by the weight to penetrate $5 \mathrm{~cm}$ into the gel. All measurement were performed in triplicate.

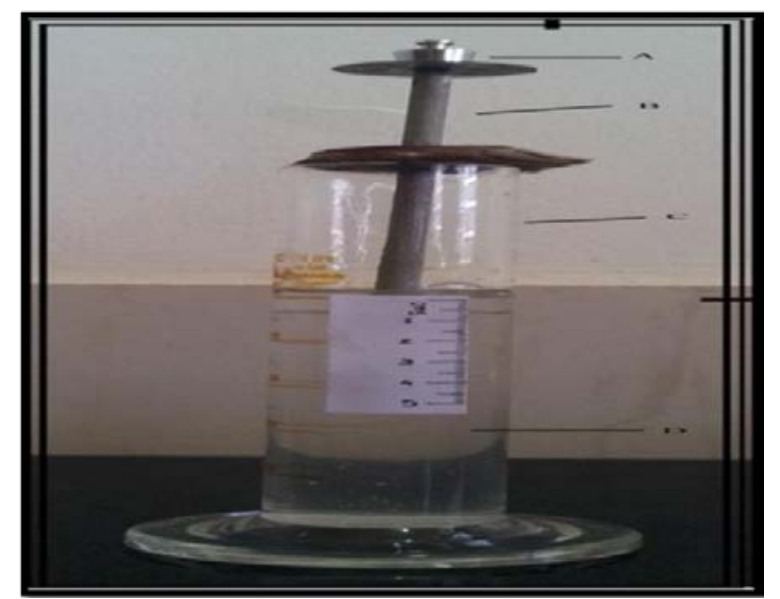

Fig. 1: Gel strength measuring device, (a) Weights (B) Device (C) Graduated Cylinder (D) Gel

\section{Mucoadhesive strength}

"Detachment Stress is the force required to detach the two surfaces of mucosa when a formulation/gel is placed in between them". The detachment stress was measured by using a modified analytical balance.

\section{i) Fabrication of equipment}

The equipment was fabricated by us in the laboratory as shown in fig. 3. A double beam physical balance was taken, both the pans were removed. The left pan was replaced with a brass wire, to which was hanged a teflon disc (A), also locally fabricated. The dimensions are $2 \mathrm{~cm}$ height and include an expanded cap of diameter $3.8 \mathrm{~cm}$ and thickness $2 \mathrm{~cm}$. Another teflon disc of $2 \mathrm{~cm}$ height and $1.5 \mathrm{~cm}$ diameter was placed right below the suspended disc upon the base of the balance. The right pan (C) was replaced with a lighter pan so that, the left pan weighs $5.25 \mathrm{gm}$ more than the right pan. The lower polypropylene block was intended to hold the mucosal tissue (D) of goat nasal mucosa and to be placed in a beaker containing simulated nasal solution pH 6.7 (E).

\section{ii) Measurement of adhesion force}

The following procedure was used for all the test formulations using the above equipment. The nasal mucosa was removed from the refrigerator and allowed to attain equilibrium with ambient conditions in the laboratory. The goat nasal mucosa was carefully excised, without removing connective and adipose tissue and washed with a simulated nasal solution. The tissue was stored in fresh simulated nasal solution. Immediately afterwards the membrane was placed over the surface of the lower teflon cylinder (B) and secured. This assembly was placed into a beaker containing simulated nasal solution $\mathrm{pH} 6.7$ at $37 \pm 2{ }^{\circ} \mathrm{C}$. From each batch, some quantity of gel was taken and applied on the lower surface of the upper teflon cylinder. The beaker containing mucosal tissue secured upon lower cylinder (B), was manipulated over the base of the balance so that, the mucosal tissue is exactly below the upper cylinder (A). The exposed part of the gel was wetted with a drop of simulated nasal solution, and then a weight of 10 gms was placed above the expanded cap, left for $10 \mathrm{~min}$. After which the gel binds with mucin. The weight was removed. Then slowly and gradually weights were added on the right side pan till the gel separates from the mucosal surface/membrane.

The weight required for complete detachment is noted (W1) (W1$5.25 \mathrm{G}$ )) gives force required for detachment expressed in weight in grams. The procedure was repeated for two more times. The average was computed and recorded.

\section{iii) Calibration of test equipment}

Initially, a gel from the same batch was taken ten times and the individual force required for complete detachment was noted and SD was calculated.

iv) Force of adhesion $(\mathbf{N})=($ bio adhesive strength $/ 1000) \times 9.81$

Bond strength $\left(\mathrm{N} / \mathrm{m}^{2}\right)=$ force of adhesion $(\mathrm{N}) /$ surface area of disk $\left(\mathrm{m}^{2}\right)$

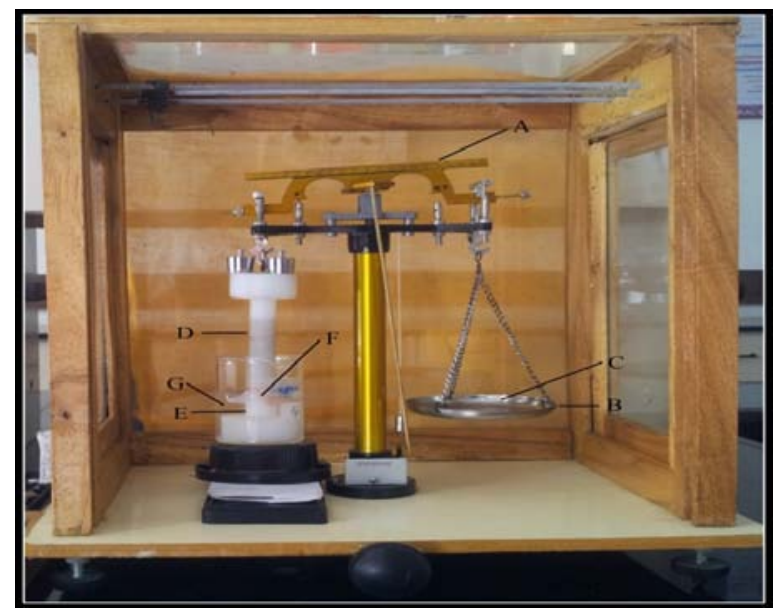

Fig. 2: Modified balance for mucoadhesive study, A: Modified balance, B: Weighing pan, C: Weight D: Gel, E: Nasal mucosa F: polypropylene cylinder

\section{Drug content [12]}

$1 \mathrm{ml}$ of the formulation was added in $10 \mathrm{ml}$ volumetric flask and make up volume up to $10 \mathrm{ml}$ with phosphate buffer $\mathrm{pH}$ 6.8. From this solution remove $1 \mathrm{ml}$ solution and make up volume up to $10 \mathrm{ml}$ with methanol. And at the fixed wavelength the absorbance of the formulation was carried out.

\section{In vitro drug release study [13]}

In vitro release study of the formulated in-situ gel was carried out by using diffusion cell through egg membrane as a biological membrane. Diffusion cell with inner diameter $1.4 \mathrm{~cm}$ was used for the study. The formulation $1 \mathrm{ml}$ were placed in donor compartment and Freshly prepared $100 \mathrm{ml}$ simulated nasal electrolyte solution (sodium chloride $0.745 \mathrm{gm}$, potassium chloride $0.129 \mathrm{gm}$, calcium chloride dehydrated $0.005 \mathrm{gm}$, distilled water q. s. $100 \mathrm{ml}$ ) in receptor compartment. Egg membranes were mounted in between donor and receptor compartment. The position of the donor compartment was adjusted so that egg membrane just touches the diffusion medium. The whole assembly was placed on the thermostatically controlled magnetic stirrer. The temperature of the medium was maintained at $37{ }^{\circ} \mathrm{C} \pm 0.5{ }^{\circ} \mathrm{C}$. $2 \mathrm{ml}$ of sample is withdrawn from receiver compartment after $30 \mathrm{~min}, 1$, 2, 3, 4, 5, 6, 7 and $8 \mathrm{~h}$ and the same volume of fresh medium is replaced. The 
withdrawn samples were diluted to $10 \mathrm{ml}$ in a volumetric flask with Methanol and analyzed by UV spectrophotometer at $239 \mathrm{~nm}$.

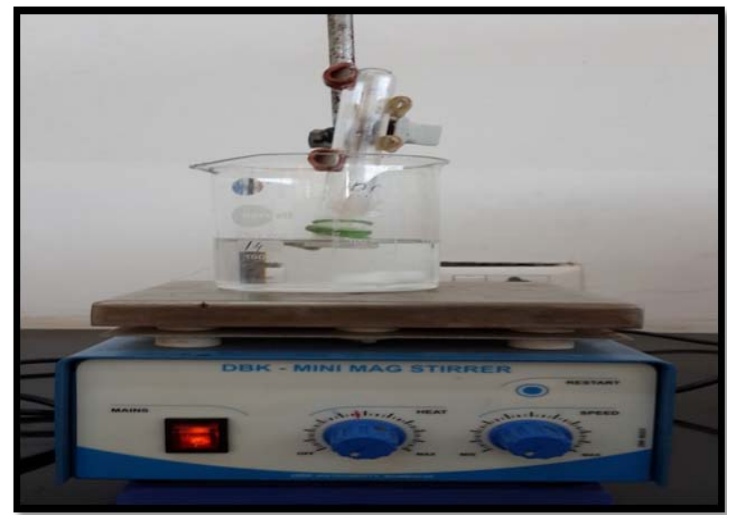

Fig. 3: Laboratory designed diffusion cell

\section{In vitro drug permeation study}

Natural membranes are utilized to determine in vitro permeation study to mimic the in vivo permeation patterns. In this experiment, goat mucosa was utilized because the respiratory area of the goat is large and it is easy to get. Fresh mucosa tissue wa removed from the nasal cavity of a goat. The tissue was placed on the diffusion cell with permeation area $0.786 \mathrm{~cm}^{-2}$. The acceptor chamber of the diffusion cell with a volume capacity $100 \mathrm{ml}$ was filled with simulated nasal fluid contain accurately $7.45 \mathrm{mg} / \mathrm{ml} \mathrm{NaCl}, 1.29 \mathrm{mg} / \mathrm{ml} \mathrm{KCl}$ and 0.32 $\mathrm{mg} / \mathrm{ml} \mathrm{CaCl}_{2} .2 \mathrm{H}_{2} \mathrm{O} .0 .5 \mathrm{ml}(10 \mathrm{mg})$ of the formulation was placed in donor compartment. At predetermined time intervals of $30 \mathrm{~min}$, $1,2,3,4,5,6,7$, and $8 \mathrm{~h} 1 \mathrm{ml}$ of sample was withdrawn from the acceptor compartment replacing the sample removed with SNF after each sampling for a period of $8 \mathrm{~h}$. Then samples are specifically diluted and absorbance was noted at $239 \mathrm{~nm}$ permeability coefficient (p) was calculated by the following formula:

$$
\mathrm{P}=(\mathrm{dQ} / \mathrm{dt}) /\left(\mathrm{C}_{0} \times \mathrm{A}\right)
$$

Where $\mathrm{dQ} / \mathrm{dt}$ is the flux or permeability rate $(\mathrm{mg} / \mathrm{h}), \mathrm{C}_{0}$ is the initial concentration in the donor compartment, and $\mathrm{A}$ is the effective surface area of the nasal mucosa.

\section{Stability studies [14]}

Table 2: Test conditions for stability study

\begin{tabular}{ll}
\hline Test conditions & \\
\hline Duration of study: & 3 mo \\
Temperature conditions: & Room temperature $25^{\circ} \mathrm{C} \pm 2{ }^{\circ} \mathrm{C}$ \\
Relative humidity conditions: & $75 \% \pm 5 \%$ \\
The frequency of testing the samples: & $30 \mathrm{D}$ \\
\hline
\end{tabular}

The formulations were evaluated mainly for their physical characteristics at the predetermined intervals of $30 \mathrm{D}$ like appearance/clarity, $\mathrm{pH}$, viscosity and drug content.

\section{RESULTS AND DISCUSSION}

\section{Preformulation study}

\section{Description}

It is White or almost white powder with the description that found in literature survey.

\section{Melting point}

Melting point of powder drug was shown in table 3

\begin{tabular}{ll}
\hline Melting point $\left({ }^{\circ} \mathrm{C}\right)$ & \\
\hline Literature & Practical \\
$272-273{ }^{\circ} \mathrm{C}$ & $273-274{ }^{\circ} \mathrm{C}$ \\
\hline
\end{tabular}

\section{Solubility}

Fluticasone Propionate is Insoluble in water. Practically soluble in Methanol, Ethanol. Isopropyl alcohol and Actone.

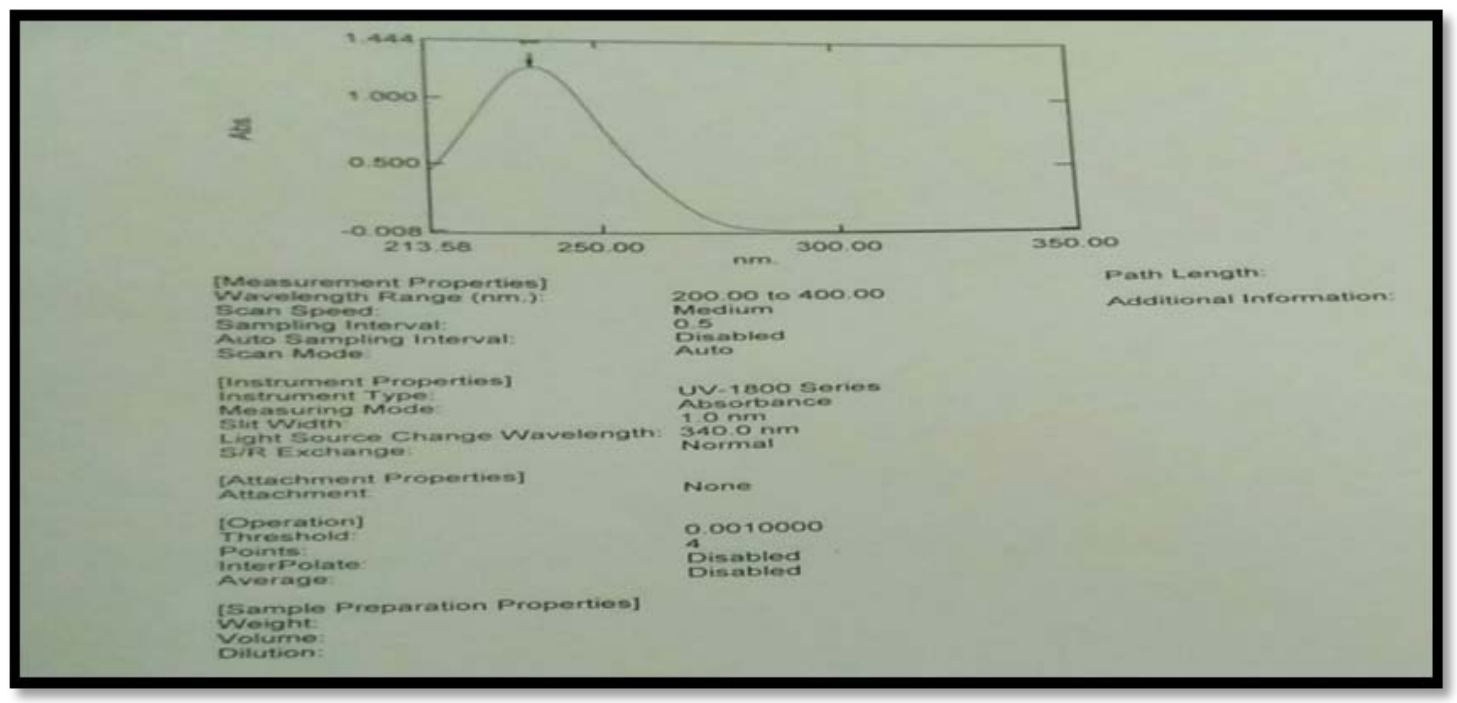

Fig. 4: UV spectra of fluticasone propionate in methanol 


\section{Ultraviolet-visible spectroscopy study}

\section{Determination of $\lambda_{\max }$ in methanol}

The UV spectrum of Fluticasone Propionate $(10 \mu \mathrm{g} / \mathrm{ml})$ exhibited wavelength of absorbance maximum at $239 \mathrm{~nm}$. This is near to the reported value. However, keeping in mind the probable concentrations likely to be encountered while carrying out In vitro release studies and considering the predicted theoretical $\lambda$ max involved, the working $\lambda$ max was decided as $239 \mathrm{~nm}$.

\section{Calibration of fluticasone propionate in methanol}

The calibration curve was found to be linear in a concentration range of $5-30 \mu \mathrm{g} / \mathrm{ml}$ having a coefficient of regression value $\mathrm{R}^{2}=$ 0.9991 at $238 \mathrm{~nm}$ is shown in fig. 3

\section{Infrared spectrum}

The absorption bands shown by Fluticasone Propionate are characteristics of the groups present in its molecular structure. The presence of absorption bands corresponding to the functional groups present in the Fluticasone Propionate confirms the identification and purity of the drug.

\section{Evaluation of nasal in-situ gel}

\section{Clarity}

All the formulations are found to be a clear solution against a dark and white background.

pH

$\mathrm{pH}$ of all the formulations was shown in the table 4.

Table 3: Absorbance of fluticasone propionate in methanol

\begin{tabular}{lll}
\hline S. No. & Concentration (ppm) & Absorbance \\
\hline 1. & 5 & 0.3451 \\
2. & 10 & 0.5384 \\
3. & 15 & 0.7483 \\
4. & 20 & 0.9878 \\
5. & 25 & 1.2104 \\
6. & 30 & 1.4277 \\
\hline
\end{tabular}

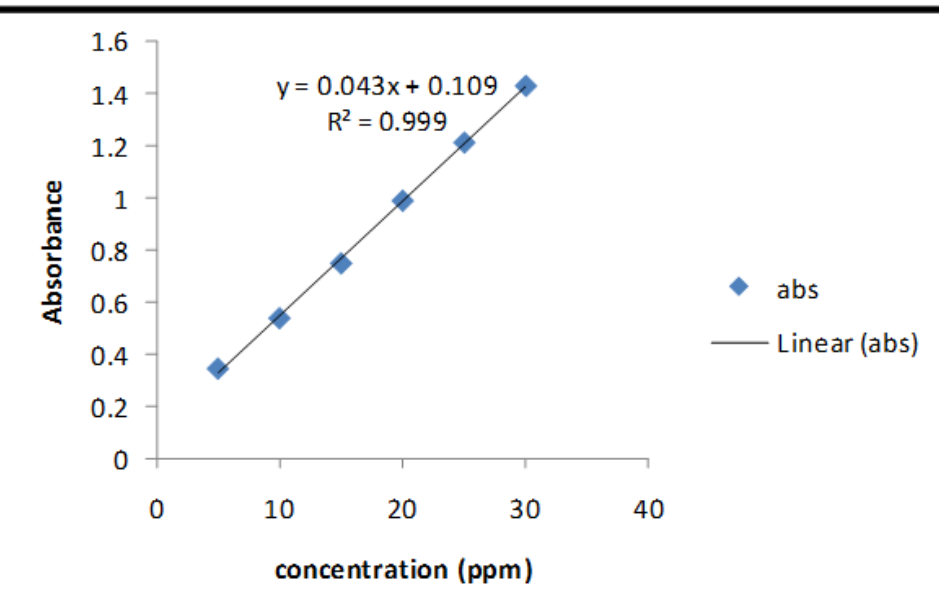

Fig. 5: Calibration curve of fluticasone propionate in methanol

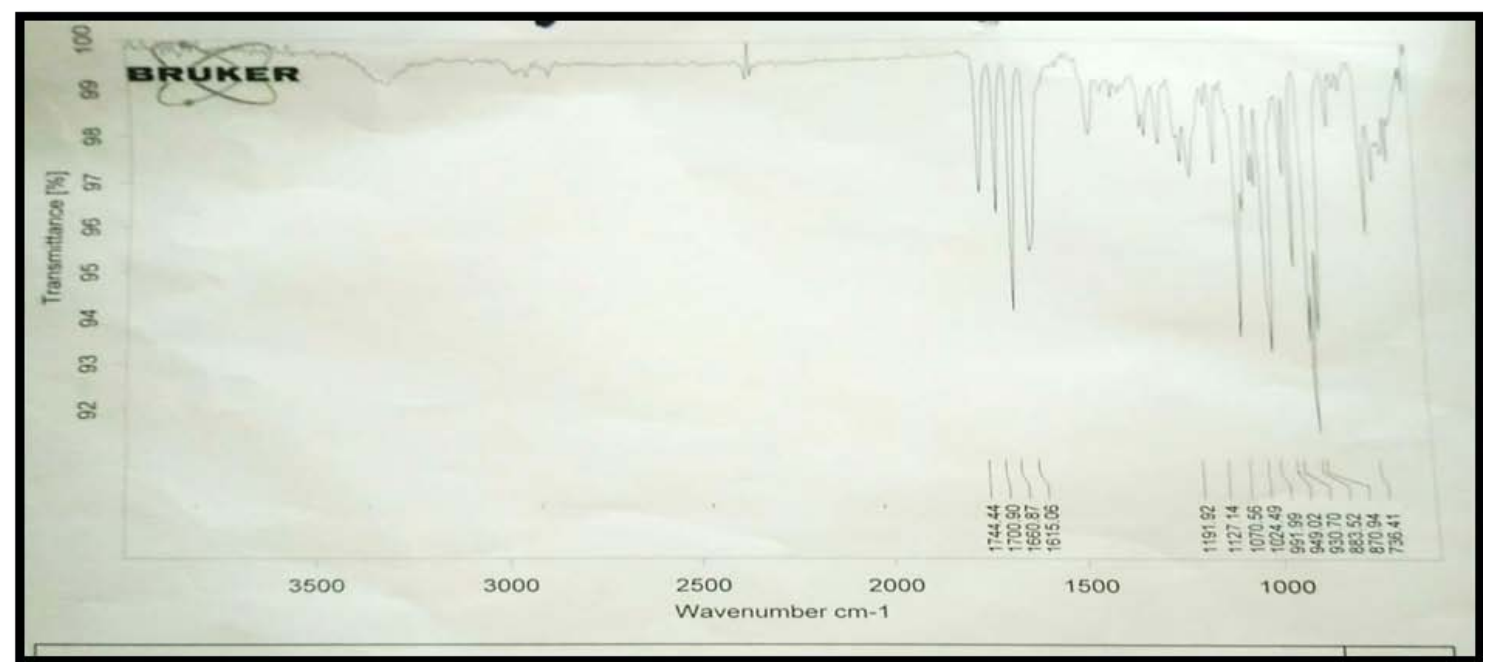

Fig. 6: FTIR spectrum of fluticasone propionate 


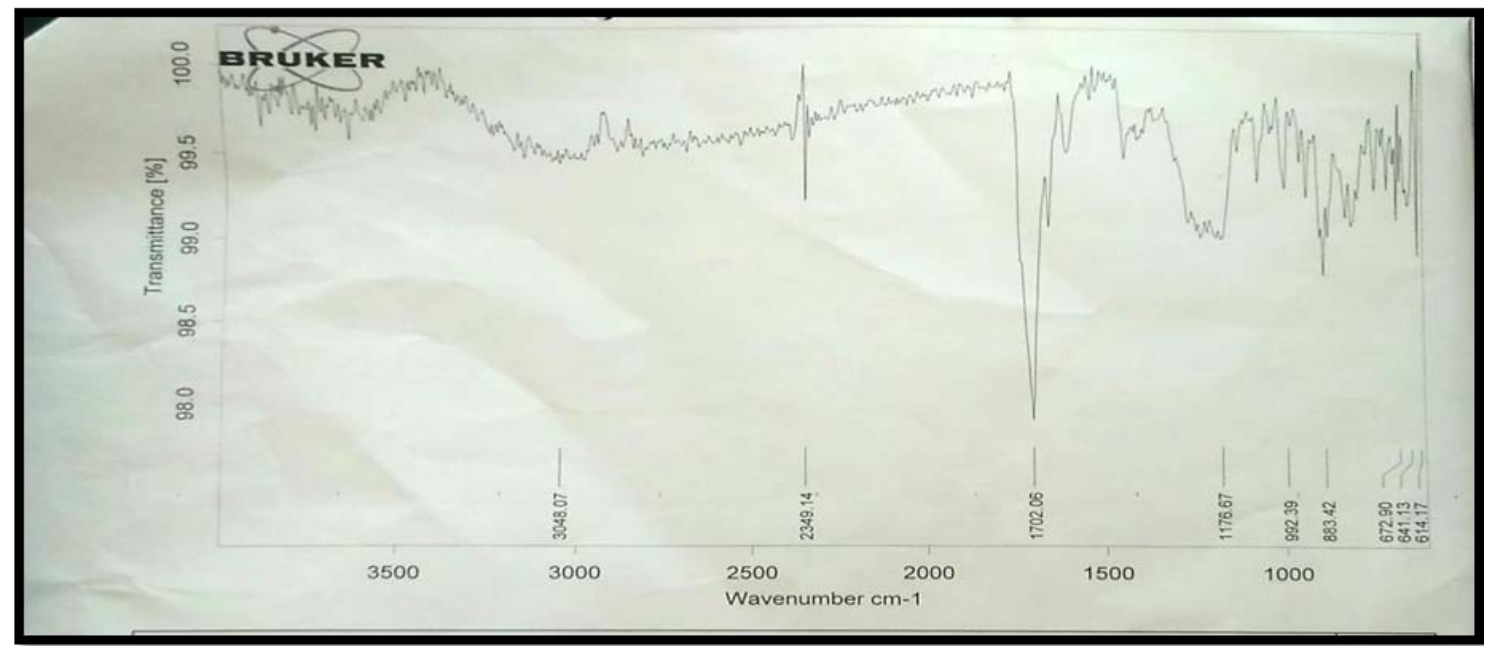

Fig. 7: FTIR spectrum of fluticasone propionate with polymers

Table 4: pH of all the formulations

\begin{tabular}{lll}
\hline S. No. & Formulation code & Observed pH ( \pm SD) \\
\hline 1 & F1 & $6.3 \pm 0.01$ \\
2 & F2 & $5.7 \pm 0.07$ \\
3 & F3 & $6.3 \pm 0.02$ \\
4 & F4 & $6.2 \pm 0.05$ \\
5 & F5 & $5.9 \pm 0.03$ \\
6 & F6 & $6.3 \pm 0.007$ \\
7 & F7 & $6.1 \pm 0.01$ \\
8 & F8 & $6.0 \pm 0.05$ \\
9 & F9 & $6.15 \pm 0.1$ \\
\hline
\end{tabular}

\section{Rheological study}

Viscosity

At Room Temperature

\begin{tabular}{|c|c|c|c|c|c|c|c|c|c|}
\hline \multirow[t]{3}{*}{ Rpm } & \multicolumn{9}{|c|}{ Viscosity (cp) at room temperature } \\
\hline & \multicolumn{9}{|c|}{ Formulation code } \\
\hline & F1 & F2 & F3 & F4 & F5 & F6 & F7 & F8 & F9 \\
\hline 5 & 430.3 & 390.3 & 402.4 & 355.9 & 330.9 & 435.9 & 334.2 & 285.3 & 529.9 \\
\hline 10 & 285.2 & 342.5 & 350.7 & 310.9 & 287.9 & 423.9 & 221.4 & 270.4 & 490.1 \\
\hline 15 & 250.5 & 290.7 & 349.5 & 289.1 & 283 & 398.4 & 207.8 & 253.2 & 435.8 \\
\hline 20 & 239.2 & 270.3 & 349.1 & 288 & 248.9 & 375.9 & 199.3 & 250 & 430.4 \\
\hline 25 & 238.4 & 265.1 & 330.6 & 217.6 & 240.1 & 345 & 184.7 & 228.9 & 392.5 \\
\hline 30 & 205.7 & 175.4 & 310.9 & 165.4 & 232 & 316.3 & 62.9 & 219.5 & 335.2 \\
\hline
\end{tabular}

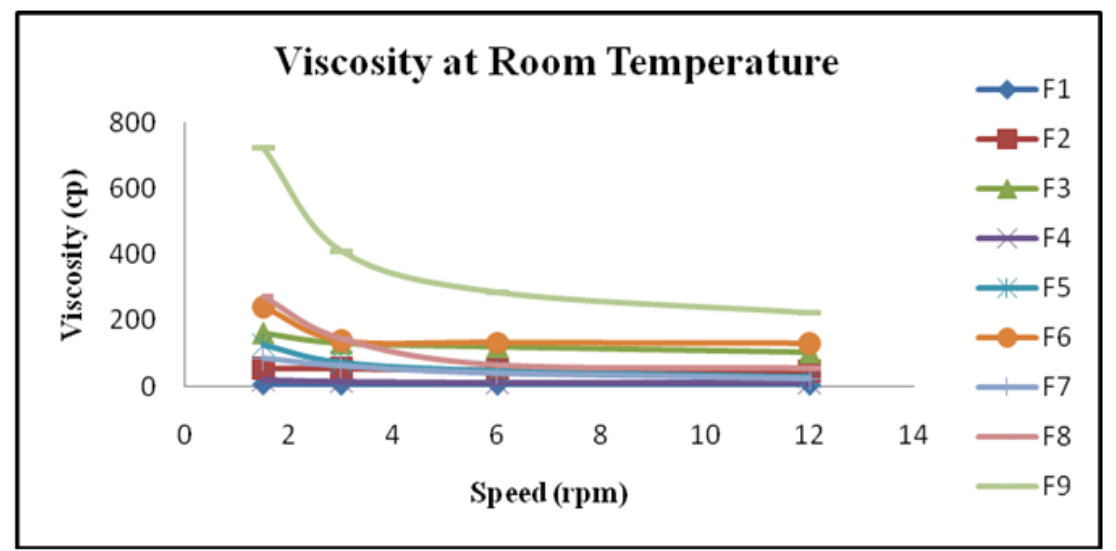

Fig. 8: Viscosity profile of formulation RT 
At $37^{\circ} \mathrm{C}$

\begin{tabular}{|c|c|c|c|c|c|c|c|c|c|}
\hline \multirow[t]{3}{*}{ Rpm } & \multicolumn{9}{|c|}{ Viscosity (cp) at $37^{\circ} \mathrm{C}$} \\
\hline & \multicolumn{9}{|c|}{ Formulation code } \\
\hline & F1 & F2 & F3 & F4 & F5 & F6 & F7 & F8 & F9 \\
\hline 5 & 476.2 & 450.1 & 575 & 479.2 & 502.4 & 575.9 & 454.1 & 430.9 & 600.9 \\
\hline 10 & 430.9 & 395.5 & 530 & 415.1 & 440 & 550.4 & 305.9 & 403.7 & 569.9 \\
\hline 15 & 396.1 & 350.9 & 490 & 365 & 370.9 & 475.7 & 290 & 350 & 535.4 \\
\hline 20 & 354.9 & 280 & 470.2 & 361.2 & 339.5 & 474.2 & 215 & 307 & 490 \\
\hline 25 & 301.2 & 280.3 & 420 & 289.9 & 335.9 & 425.2 & 192.2 & 292.5 & 455.9 \\
\hline 30 & 270.3 & 253 & 375.8 & 279 & 295.7 & 399 & 153.3 & 290.1 & 415.7 \\
\hline
\end{tabular}

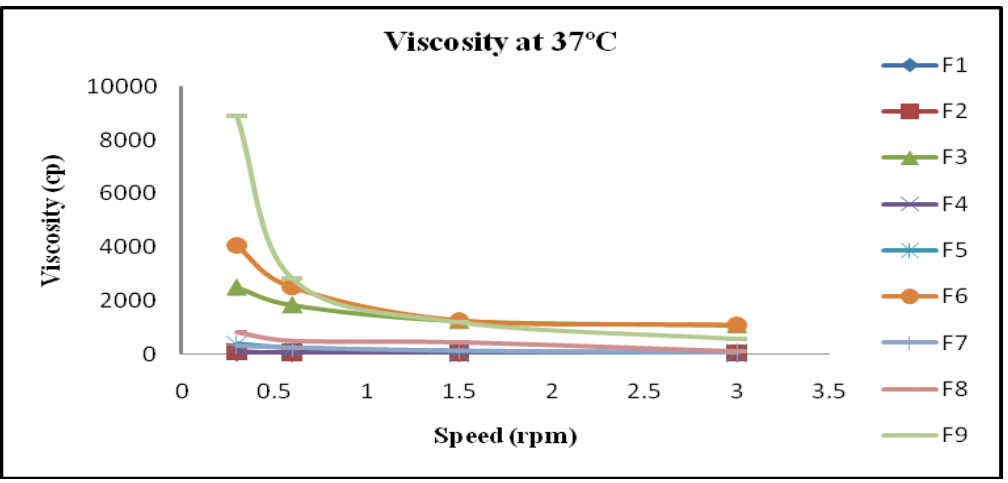

Fig. 9: Viscosity profile of formulations at $37^{\circ} \mathrm{C}$

Gelling capacity

\begin{tabular}{ll}
\hline Formulation code & Gelling capacity \\
\hline F1 & + \\
F2 & + \\
F3 & ++ \\
F4 & +++ \\
F5 & ++ \\
F6 & ++++ \\
F7 & ++ \\
F8 & +++ \\
F9 & ++++ \\
\hline
\end{tabular}

(+: Gel formed after a few minutes, dissolves rapidly,++: Immediate gelation, remains for few hours,+++: Immediate gelation, remains for extended period.)

Gelling strength

\begin{tabular}{llll}
\hline S. No. & Formulation code & Gel strength $(\mathbf{s e c})(\mathbf{\pm S D})$ at RT & Gel strength (sec) $(\mathbf{\pm S D})$ at $3 \mathbf{~}^{\circ} \mathbf{c}$ \\
\hline 1 & F1 & $0.44 \pm 0.007$ & $0.55 \pm 0.007$ \\
2 & F2 & $0.61 \pm 0.007$ & $0.87 \pm 0.007$ \\
3 & F3 & $0.82 \pm 0.007$ & $1.3 \pm 0.007$ \\
4 & F4 & $0.77 \pm 0.007$ & $0.98 \pm 0.007$ \\
5 & F5 & $0.86 \pm 0.007$ & $0.97 \pm 0.007$ \\
6 & F6 & $0.95 \pm 0.007$ & $2.05 \pm 0.007$ \\
7 & F7 & $0.75 \pm 0.007$ & $0.89 \pm 0.007$ \\
8 & F8 & $1.6 \pm 0.03$ & $2.34 \pm 0.007$ \\
9 & F9 & $2.03 \pm 0.007$ & $2.36 \pm 0.007$ \\
\hline
\end{tabular}

\section{Mucoadhesive strength}

At RT

\begin{tabular}{lll}
\hline Formulation code & Detachment force $(\mathbf{N}) \mathbf{( \pm S D )}$ & Bond strength (N/m2)( \pm S. D) \\
\hline F1 & $0.04411 \pm 0.001$ & $0.00241 \pm 0.005$ \\
F2 & $0.05036 \pm 0.002$ & $0.0027 \pm 0.002$ \\
F3 & $0.05637 \pm 0.005$ & $0.0031 \pm 0.005$ \\
F4 & $0.06394 \pm 0.003$ & $0.0035 \pm 0.001$ \\
F5 & $0.06725 \pm 0.007$ & $0.0037 \pm 0.0001$ \\
F6 & $0.07257 \pm 0.001$ & $0.0040 \pm 0.001$ \\
F7 & $0.07762 \pm 0.001$ & $0.0042 \pm 0.002$ \\
F8 & $0.08010 \pm 0.001$ & $0.0044 \pm 0.002$ \\
F9 & $0.08469 \pm 0.001$ & $0.0046 \pm 0.005$ \\
\hline
\end{tabular}


At $37^{\circ} \mathrm{C}$

\begin{tabular}{lll}
\hline Formulation code & Detachment force $\mathbf{( N )}(\mathbf{+ S D})$ & Bond strength (N/m2)( $\mathbf{S}$. D) \\
\hline F1 & $0.066 \pm 0.00031$ & $0.0031 \pm 0.005$ \\
F2 & $0.068 \pm 0.0001$ & $0.0037 \pm 0.001$ \\
F3 & $0.077 \pm 0.005$ & $0.0042 \pm 0.001$ \\
F4 & $0.082 \pm 0.001$ & $0.0045 \pm 0.002$ \\
F5 & $0.084 \pm 0.0007$ & $0.0046 \pm 0.005$ \\
F6 & $0.087 \pm 0.004$ & $0.0048 \pm 0.001$ \\
F7 & $0.090 \pm 0.0003$ & $0.0050 \pm 0.005$ \\
F8 & $0.091 \pm 0.007$ & $0.0089 \pm 0.002$ \\
F9 & $0.092 \pm 0.00031$ & $0.0051 \pm 0.002$ \\
\hline
\end{tabular}

\section{Drug content}

\begin{tabular}{ll}
\hline Formulation code & Drug content $(\%) \mathbf{( S D )}$ \\
\hline F1 & $92.10 \pm 0.007$ \\
F2 & $89 \pm 0.007$ \\
F3 & $93 \pm 0.007$ \\
F4 & $92.10 \pm 0.007$ \\
F5 & $98.68 \pm 0.007$ \\
F6 & $102 \pm 0.007$ \\
F7 & $93 \pm 0.007$ \\
F8 & $96.05 \pm 0.007$ \\
F9 & $98.68 \pm 0.007$ \\
\hline
\end{tabular}

In vitro drug release

\begin{tabular}{|c|c|c|c|c|c|c|c|c|c|}
\hline \multicolumn{10}{|c|}{ Cumulative drug release $(\%)( \pm S D)$} \\
\hline Time in (H) & F1 & F2 & F3 & F4 & F5 & F6 & F7 & F8 & F9 \\
\hline 0 & 0 & 0 & 0 & 0 & 0 & 0 & 0 & 0 & 0 \\
\hline \multirow[t]{2}{*}{$30 \mathrm{~min}$} & $4.25 \pm$ & $6.21 \pm$ & $10.11 \pm$ & $3.47 \pm$ & $8.16 \pm$ & $23.39 \pm$ & $8.16 \pm$ & $23.78 \pm$ & $23.78 \pm$ \\
\hline & 0.001 & 0.05 & 0.007 & 0.001 & 0.02 & 0.05 & 0.007 & 0.09 & 0.1 \\
\hline \multirow[t]{2}{*}{1} & $8.16 \pm$ & $11.68 \pm$ & $17.93 \pm$ & $6.21 \pm$ & $17.43 \pm$ & $23.79 \pm$ & $21.83 \pm$ & $24.57 \pm$ & $33.55 \pm$ \\
\hline & 0.04 & 0.019 & 0.05 & 0.005 & 0.001 & 0.005 & 0.007 & 0.1 & 0.09 \\
\hline \multirow[t]{2}{*}{2} & $15.97 \pm$ & $33.55 \pm$ & $33.55 \pm$ & $12.07 \pm$ & $29.65 \pm$ & $29.65 \pm$ & $29.26 \pm$ & $29.65 \pm$ & $40.98 \pm$ \\
\hline & 0.01 & 0.009 & 0.007 & 0.005 & 0.02 & 0.001 & 0.007 & 0.05 & 0.001 \\
\hline \multirow[t]{2}{*}{3} & $27.69 \pm$ & $45.27 \pm$ & $45.28 \pm$ & $27.30 \pm$ & $32.38 \pm$ & $35.51 \pm$ & $39.42 \pm$ & $35.90 \pm$ & $49.58 \pm$ \\
\hline & 0.001 & 0.001 & 0.001 & 0.05 & 0.007 & 0.001 & 0.02 & 0.05 & 0.009 \\
\hline \multirow[t]{2}{*}{4} & $47.23 \pm$ & $46.45 \pm$ & $46.06 \pm$ & $48.79 \pm$ & $39.03 \pm$ & $57 \pm$ & $55.05 \pm$ & $56.61 \pm$ & $70.28 \pm$ \\
\hline & 0.009 & 0.007 & 0.034 & 0.04 & 0.5 & 0.004 & 0.009 & 0.001 & 0.07 \\
\hline \multirow[t]{2}{*}{5} & $60.90 \pm$ & $53.10 \pm$ & $58.96 \pm$ & $58.95 \pm$ & $46.45 \pm$ & $61.30 \pm$ & $64.04 \pm$ & $61.69 \pm$ & $78.50 \pm$ \\
\hline & 0.001 & 0.001 & 0.007 & 0.001 & 0.09 & 0.05 & 0.01 & 0.001 & 0.2 \\
\hline \multirow[t]{2}{*}{6} & $62.80 \pm$ & $58.18 \pm$ & $62.09 \pm$ & $60.13 \pm$ & $58.57 \pm$ & $68.30 \pm$ & $71.07 \pm$ & $69.90 \pm$ & $85.54 \pm$ \\
\hline & 0.02 & 0.05 & 0.009 & 0.007 & 0.001 & 0.001 & 0.005 & 0.009 & 0.007 \\
\hline \multirow[t]{2}{*}{7} & $66.78 \pm$ & $68.73 \pm$ & $66.39 \pm$ & $65.61 \pm$ & $67.95 \pm$ & $80.46 \pm$ & $72.64 \pm$ & $82.02 \pm$ & $96.09 \pm$ \\
\hline & 0.2 & 0.4 & 0.001 & 0.001 & 0.007 & 0.007 & 0.001 & 0.009 & 0.001 \\
\hline \multirow[t]{2}{*}{8} & $72.64 \pm$ & $82.62 \pm$ & $79.68 \pm$ & $72.64 \pm$ & $80.85 \pm$ & $92.97 \pm$ & $86.71 \pm$ & $94.14 \pm$ & $98.45 \pm$ \\
\hline & 0.05 & 0.04 & 0.009 & 0.001 & 0.001 & 0.004 & 0.007 & 0.004 & 0.001 \\
\hline
\end{tabular}

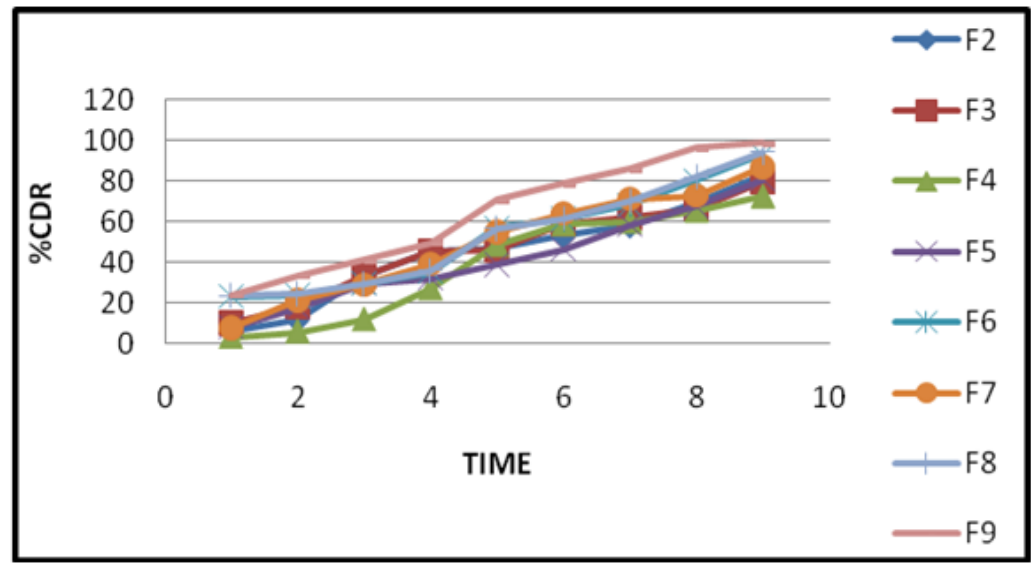

Fig. 10: In vitro drug release profile 
Drug permeation study

\begin{tabular}{|c|c|c|c|c|c|c|c|c|c|}
\hline Time & F1 & F2 & F3 & F4 & F5 & F6 & F7 & F8 & F9 \\
\hline $30 \mathrm{Min}$ & 15.97 & 16.75 & 15.58 & 12.07 & 8.55 & 9.33 & 5.42 & 8.16 & 8.94 \\
\hline $1 \mathrm{~h}$ & 40.58 & 39.41 & 23.79 & 14.02 & 14.41 & 12.85 & 7.77 & 12.46 & 14.02 \\
\hline $2 \mathrm{~h}$ & 55.82 & 56.99 & 49.96 & 30.43 & 19.49 & 20.27 & 10.11 & 23.01 & 26.52 \\
\hline $3 \mathrm{~h}$ & 80.44 & 81.22 & 59.73 & 45.27 & 46.84 & 33.16 & 13.63 & 37.07 & 38.24 \\
\hline $4 \mathrm{~h}$ & 85.14 & 92.17 & 65.99 & 64.42 & 70.67 & 61.29 & 23.40 & 53.09 & 57.39 \\
\hline $5 \mathrm{~h}$ & 90.218 & 93.35 & 74.59 & 74.58 & 76.54 & 73.41 & 38.24 & 62.86 & 78.11 \\
\hline $6 \mathrm{~h}$ & 92.18 & 95.70 & 80.85 & 80.06 & 80.84 & 81.62 & 51.53 & 78.10 & 78.49 \\
\hline $7 \mathrm{~h}$ & 95.71 & 95.27 & 97.26 & 95.30 & 97.65 & 84.36 & 64.82 & 82.41 & 89.83 \\
\hline $8 \mathrm{~h}$ & 97.28 & 98.07 & 98.45 & 97.27 & 98.05 & 94.14 & 92.71 & 93.35 & 98.83 \\
\hline
\end{tabular}

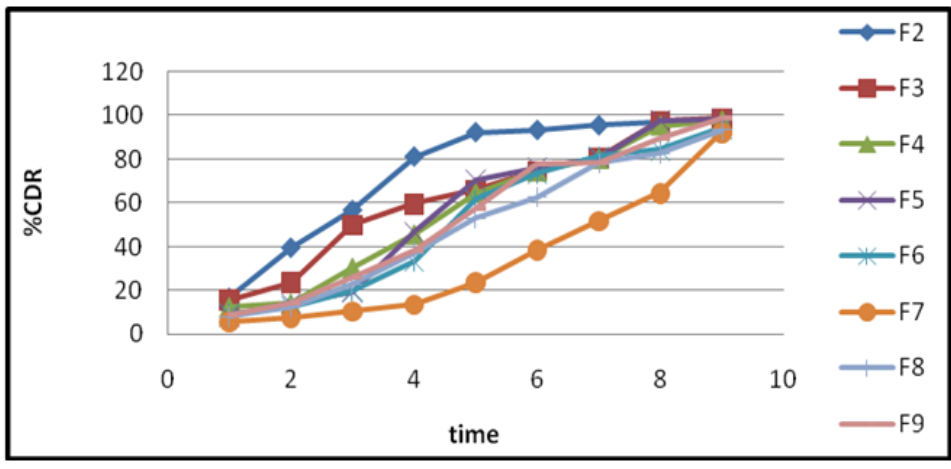

Fig. 11: In vitro drug permeation study profile

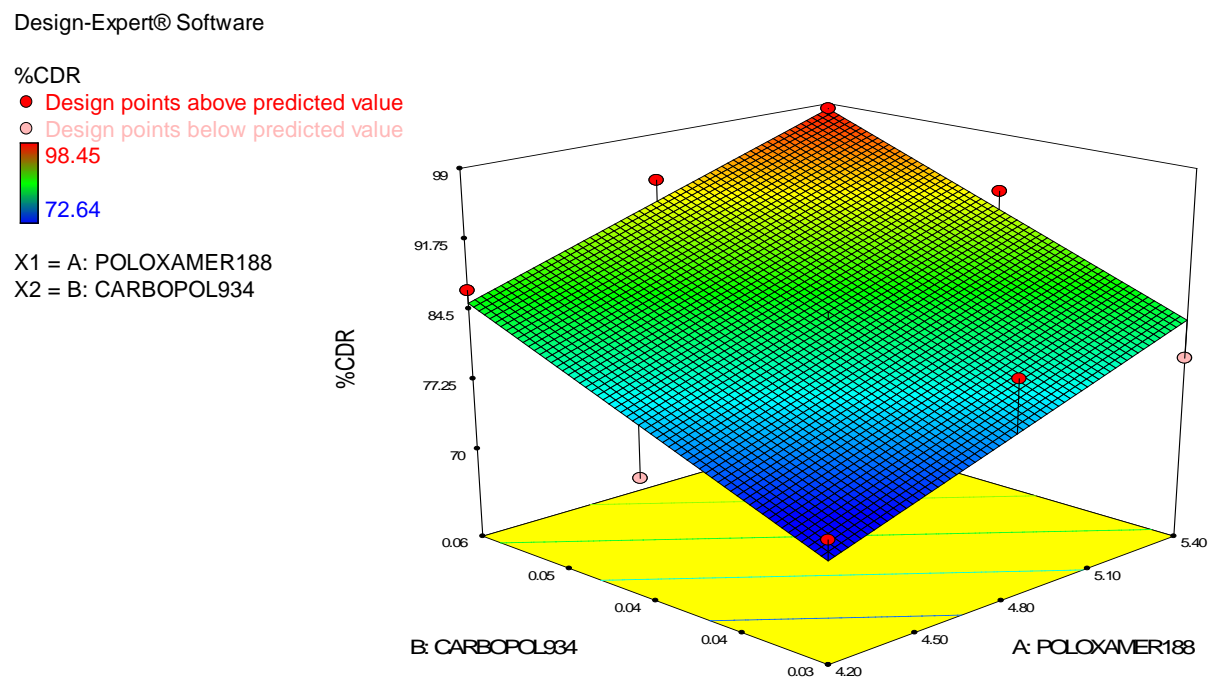

Fig. 12: Surface response plot showing effect of poloxamer 188 and carbopol 934 on $\%$ drug release

Stability study data for F9 batch

\begin{tabular}{|c|c|c|c|c|c|c|c|c|c|c|}
\hline \multirow[t]{2}{*}{ S. No. } & \multirow[t]{2}{*}{ Observation } & & \multirow{2}{*}{\multicolumn{2}{|c|}{ Before stability testing }} & \multicolumn{6}{|c|}{ During study } \\
\hline & & & & & \multicolumn{2}{|l|}{$30 \mathrm{D}$} & \multicolumn{2}{|l|}{$30 \mathrm{D}$} & \multicolumn{2}{|l|}{$30 \mathrm{D}$} \\
\hline 1. & Clarity & & \multicolumn{2}{|l|}{ Clear } & \multicolumn{2}{|l|}{ Clear } & \multicolumn{2}{|l|}{ Clear } & \multicolumn{2}{|l|}{ Clear } \\
\hline 2. & \multicolumn{2}{|l|}{ Visual appearance } & \multicolumn{2}{|c|}{ Transparent } & \multicolumn{2}{|c|}{ Transparent } & \multicolumn{2}{|c|}{ Transparent } & \multicolumn{2}{|c|}{ Transparent } \\
\hline 3. & \multicolumn{2}{|l|}{$\mathrm{pH}$} & $6.15 \pm 0$ & & \multicolumn{2}{|c|}{$6.16 \pm 0.01$} & \multicolumn{2}{|c|}{$6.15 \pm 0.01$} & \multicolumn{2}{|c|}{$6.15 \pm 0.01$} \\
\hline \multirow[t]{7}{*}{4.} & \multirow[t]{7}{*}{ Viscosity (rpm) } & & At RT & At $37^{\circ} \mathrm{C}$ & At RT & At $37^{\circ} \mathrm{C}$ & At RT & At $37^{\circ} \mathrm{C}$ & At RT & At $37^{\circ} \mathrm{C}$ \\
\hline & & 5 & 529.9 & 600.9 & 530 & 601 & 531 & 602.3 & 529.5 & 530 \\
\hline & & 10 & 490.1 & 568.9 & 489 & 567.8 & 490 & 568.2 & 489.7 & 568.4 \\
\hline & & 15 & 435.8 & 535.4 & 435 & 534.9 & 435.9 & 535.1 & 436 & 534.8 \\
\hline & & 20 & 430.4 & 490 & 430 & 491.3 & 429.5 & 430.5 & 430.4 & 431.7 \\
\hline & & 25 & 392.5 & 455.9 & 391 & 455.2 & 392.4 & 444.6 & 393.7 & 445.3 \\
\hline & & 30 & 335.2 & 415.7 & 335 & 415 & 334.5 & 414.6 & 335.6 & 415.5 \\
\hline 5. & Drug content & & $98.68 \pm$ & & $98.69=$ & & 98.70 & & $98.67=$ & \\
\hline
\end{tabular}

Formulations at room temperature were found to be stable up to 3 mo. There is no change in drug content, pH, clarity and viscosity. 


\section{Stability study}

Stability study of optimized F9 batch was shown below

\section{CONCLUSION}

The nasal route of administration for systemic drug delivery offers a number of advantages compared to conventional routes, especially for peptide and protein drugs. Nasal delivery is being increasingly considered to be an alternative route for drugs that currently require the parenteral administration to achieve good efficacy, or where circumstances make oral delivery difficult. The nasal route is an alternative for several reasons, including rapid absorption into the systemic circulation, elimination of hepatic first pass metabolism and low proteolytic activity in the nasal mucosa.

From the above investigation, the temperature sensitive in-situ gel of Fluticasone Propionate (2\%) for controlling the drug release in the nasal tissues. Two polymers have been used i.e. Poloxamer 188 which is Temperature sensitive and also act as a gelling agent and Cabopol 934 act as pH sensitive mucoadhesive polymer.

These conditions resemble the physiological conditions of the nose. The Temperature sensitive in-situ nasal gel so prepared were characterized for its clarity, $\mathrm{pH}$, viscosity, gel strength, mucoadhesive strength, drug content, in vitro drug release and in vitro permeation.

The following conclusion can be drawn from the present study:

1) A preformulation evaluation study has proven the identity and purity of. Fluticasone Propionate.

2) Infrared spectroscopy studies of Fluticasone Propionate alone and their physical mixture revealed that, is compatible with all polymers used.

3) All formulations were examined for visual appearance and were found to be transparent.

4) $\mathrm{pH}$ of all the formulations was found to be in between the nasal $\mathrm{pH}$ range (4.5-6.5)which is in tolerable range in contact with nasal tissues.

5) The viscosities of all the formulations were greatly affected by the concentration of Poloxamer-188 and Carbopol 934. A formulation containing Poloxamer- $18 \%$ and $0.2 \% \mathrm{w} / \mathrm{v}$ Carbopol 934 showed optimum viscosity and exhibited pseudoplastic behaviour.

6) Gel strength and Mucoadhesive strength of formulations resemble to the viscosity results.

7) Drug content of all the formulations was found to be in between $89-98.68 \%$ which was in acceptable range.

8) The release kinetics results obtained indicate that formulation containing Poloxamer-188 18\% and $0.2 \% \mathrm{w} / \mathrm{v}$ Carbopol 934 showed the highest release i.e. $98.45 \%$ after $8 \mathrm{~h}$ which indicates that the formulation has shown prolonged release. This optimized formula was also confirmed by design expert 7.0.0 optimization software.

9) The optimized formulation F9 showed good stability and no change in any physical characteristics over a 3 mo period at $25{ }^{\circ} \mathrm{C} \pm 2$ ${ }^{\circ} \mathrm{C}$ Temperature and $75 \% \pm 5 \%$ Relative Humidity.

Thus Fluticasone Propionate 2\% Temperature sensitive in-situ nasal gel formulation fulfils all necessary parameters required for nasal use. This optimized formulation having improved viscosity and better mucoadhesive property may improve the bioavailability of nasal administration of Fluticasone Propionate in gel form and can be alternative to the conventionally administered oral formulation. Also, the common problem of food interaction seen with oral administration can be overcome by the use of the novel dosage form developed in this study.

\section{CONFLICT OF INTERESTS}

\section{Declare none}

\section{REFERENCES}

1. Bommer R. Drug delivery-nasal route. In: swarbrick J, Boylan JC. $2^{\text {nd }}$ edition. Encyclopedia of pharmaceutical technology; 2011;2:854-855, 860 .

2. Jadhav AJ, Gondkar SB, Saudagar RB. A review on nasal drug delivery system. World J Pharm Pharm Sci 2014;3:231-54.

3. Gowada DV, Tanuja D, Mohammed S Khan, Desai J, Shivakumar HG. Formulation and evaluation of In-Situ gel of diltiazem hydrochloride for nasal delivery, Scholars Res Library 2011;3:371-2.

4. Drug bank [Internet]; 2014. Available from: http://www.drugbank.ca/drugs/DB00315. [Last accessed on 15 Jan 2014]

5. More PK, Saudagar RB, Gondkar SB. In-situ gel: a novel approaches for nasal drug delivery system. World J Pharm Res 2015;4:686-708.

6. Jadhav AJ, Gondkar SB, Saudagar RB. A review on nasal drug delivery system. World J Pharm Pharm Sci 2014;3:231-54.

7. Raymond CR, Paul JS, Sian CO. Handbook of pharmaceutical excipients. 5th ed. Pharmaceutical Press; 2006. p. 61-63, 120123, 545-550, 690-692, 821-823.

8. Mark Gibson. Pharmaceutical Preformulation and Formulation. $2^{\text {nd }}$ Edition. Drugs and Pharmaceutical Sciences; 1999. p. 457465, 489, 308.

9. Infrared Spectroscopy. In: Pavia DL, Lampman GM, Kriz GS, Vyayan JR. editors. Spectroscopy. New Delhi: Cengage learning; 2011. p. 38-9.

10. Bolten S, Bon C. Factorial Designs. Experimental design in clinical trials. 5th ed. Pharmaceutical Statics Practical and Clinical Applications. Informa healthcare. Marcel Dekker; 2010. p. 203:222-236, 265-280

11. Brookfield Engineering Labs., Inc., Brookfield Viscometer; type DV-II+PRO Instruction manual, Manual No. M03-165-E0211; 2015. p. $5-23$.

12. Bajpaivibha. In-situ gel nasal drug delivery system-a review. Int J Pharma Sci 2016;4:577-80.

13. Sahu BP, Sharma HK. Development and evaluation of mucoadhesive nasal gel of felodipine prepared with the mucoadhesive substance of dillleniaindica L. Asian J Pharm Sci 2011;5:175-87.

14. Jaiswal J, Anantvar SP, Narkhede MR, Gore SV, Mehta K. Formulation and evaluation of thermoreversible in-situ nasal gel of metoprolol succinate. Int J Pharm Pharm Sci 2012;4:96102.

\section{How to cite this article}

- $\quad$ RB Saudagar, Sarika V Khandbahale. Formulation development and evaluation of nasal in-situ gel of fluticasone propionate. Int J Curr Pharm Res 2017;9(5):45-54. 